\title{
THE MECHANISM OF LIVER SIZE CONTROL IN MAMMALS: A NOVEL ANIMAL STUDY
}

\author{
K. YOSHIZATO ${ }^{1,2}$, C. TATENO ${ }^{1} \&$ R. UTOH $^{3}$ \\ ${ }^{1}$ PhoenixBio, Kagamiyama, Higashihiroshima, Japan \\ ${ }^{2}$ Osaka City University Gradate School of Medicine, Osaka, Japan. \\ ${ }^{3}$ Institute of Advanced Biomedical Engineering and Science, Tokyo Women's Medical University, \\ Shinju-ku, Tokyo, Japan.
}

\section{ABSTRACT}

The liver, the organ that metabolizes food and chemicals and delivers nutrients to body tissues, is essential to vertebrate life. The architecture of the liver is adequately designed such that its activity is precisely aligned with individual body requirements, neither over- nor underperforming. Thus, liver weight $\left(\mathrm{W}_{\text {liver }}\right)$ is correlated with body weight $\left(\mathrm{W}_{\text {body }}\right)$. In any vertebrate species, the ratio $\left(\mathrm{R}_{\mathrm{L} / \mathrm{B}}\right)$ of $\mathrm{W}_{\text {liver }}$ to $\mathrm{W}_{\text {body }}$ is relatively constant among adults with fully functional mature livers. Recently, we created a mouse (chimeric mouse) with a liver composed of xenogenic hepatocytes and showed that the mouse can be used as a novel experimental animal model to study the mechanism of $\mathrm{R}_{\mathrm{L} / \mathrm{B}}$ optimization. Liver tissue is generated via two different processes, embryonic liver organogenesis and liver regeneration in adults, and $\mathrm{R}_{\mathrm{L} / \mathrm{B}}$ is optimized in the course of these biological phenomena. Although liver organogenesis and regeneration have been abundantly studied and mice with chimeric liver have been characterized intensively, very few studies have investigated these biological processes in the mouse model with such chimerism in relation to the regulation of $\mathrm{R}_{\mathrm{L} / \mathrm{B}}$. In this article, we review these previous studies on liver embryogenesis, regeneration and liver-chimeric mice from a viewpoint of $\mathrm{R}_{\mathrm{L} / \mathrm{B}}$ regulation to make it appeal that the chimeric mouse is a novel and useful animal model to investigate the $\mathrm{R}_{\mathrm{L} / \mathrm{B}}$ optimization at the cellular and molecular levels.

Keywords: cell cycle, cell proliferation, chimerism, DNA synthesis, hepatocytes, liver organogenesis, liver regeneration, termination of DNA synthesis, xenotransplantation.

\section{INTRODUCTION: LIVER MASS IS DETERMINED BY BODY WEIGHT}

The weight $\left(\mathrm{W}_{\text {liver }}\right)$ of a vertebrate liver is empirically correlated with body weight $\left(\mathrm{W}_{\text {body }}\right)$. The ratio $\left(\mathrm{R}_{\mathrm{L} / \mathrm{B}}\right)$ of $\mathrm{W}_{\text {liver }}$ to $\mathrm{W}_{\text {body }}$ of individuals within a vertebrate species deviates very little. For example, the $\mathrm{R}_{\mathrm{L} / \mathrm{B}}$ of humans, dogs, rats and mice are 2.4-2.6\% [1], 2.6-3.2\% [2], 4.0-4.5\% [3] and 5\%, respectively. Data obtained from orthotropic liver transplants in humans and animals show that an individual's $\mathrm{R}_{\mathrm{L} / \mathrm{B}}$ value is critical: when the liver mass is not in the proper ratio to body weight, the individual promptly initiates reactions to restore the appropriate $\mathrm{R}_{\mathrm{L} / \mathrm{B}}$ value. The correlation between $\mathrm{W}_{\text {liver }}$ and $\mathrm{W}_{\text {body }}$ of a vertebrate is given by the following equation: $\mathrm{W}_{\text {liver }}=0.33 \times \mathrm{W}_{\text {body }}{ }^{0.87}$ [4]. These empirical observations allow us to postulate a 'liver weight $\left(\mathrm{R}_{\mathrm{L} / \mathrm{B}}\right)$ optimization' rule that describes the relationship between the liver and individual body size and predicts liver mass from body weight using the above equation.

Occasionally, surgeons must transplant an intact liver into a recipient who is larger than the donor (small-for-size liver transplant) (Fig. 1) [1]. For example, a liver weighing $693 \mathrm{~g}$ from a 7-year-old boy whose body weight was $23 \mathrm{~kg}$ was removed as the donor liver (liver donor $_{\text {) }}$ and orthotopically transplanted to a 44-year-old woman weighing $47.5 \mathrm{~kg}$, whose 1,768 -g liver had been removed at the time of transplant. The original donor and host $\mathrm{R}_{\mathrm{L} / \mathrm{B}} \mathrm{S}$ were 3.01 and 3.72 , respectively. The $\mathrm{R}_{\mathrm{L} / \mathrm{B}}$ of the host decreased from 3.72 to 1.46 . Over a 2-week period, the donor liver grew rapidly within its new host, increasing linearly at approximately $70 \mathrm{~g} /$ day, until a new hepatic mass $(\sim 1.6 \mathrm{~kg})$ was achieved at 12 days post-transplantation. The restored $\mathrm{R}_{\mathrm{L} / \mathrm{B}}$ was $\sim 3.4$, which was close to the original host $\mathrm{R}_{\mathrm{L} / \mathrm{B}}$ (3.72) [1]. Kam et al. [2] showed that the host size determines the liver size in an orthotopic 


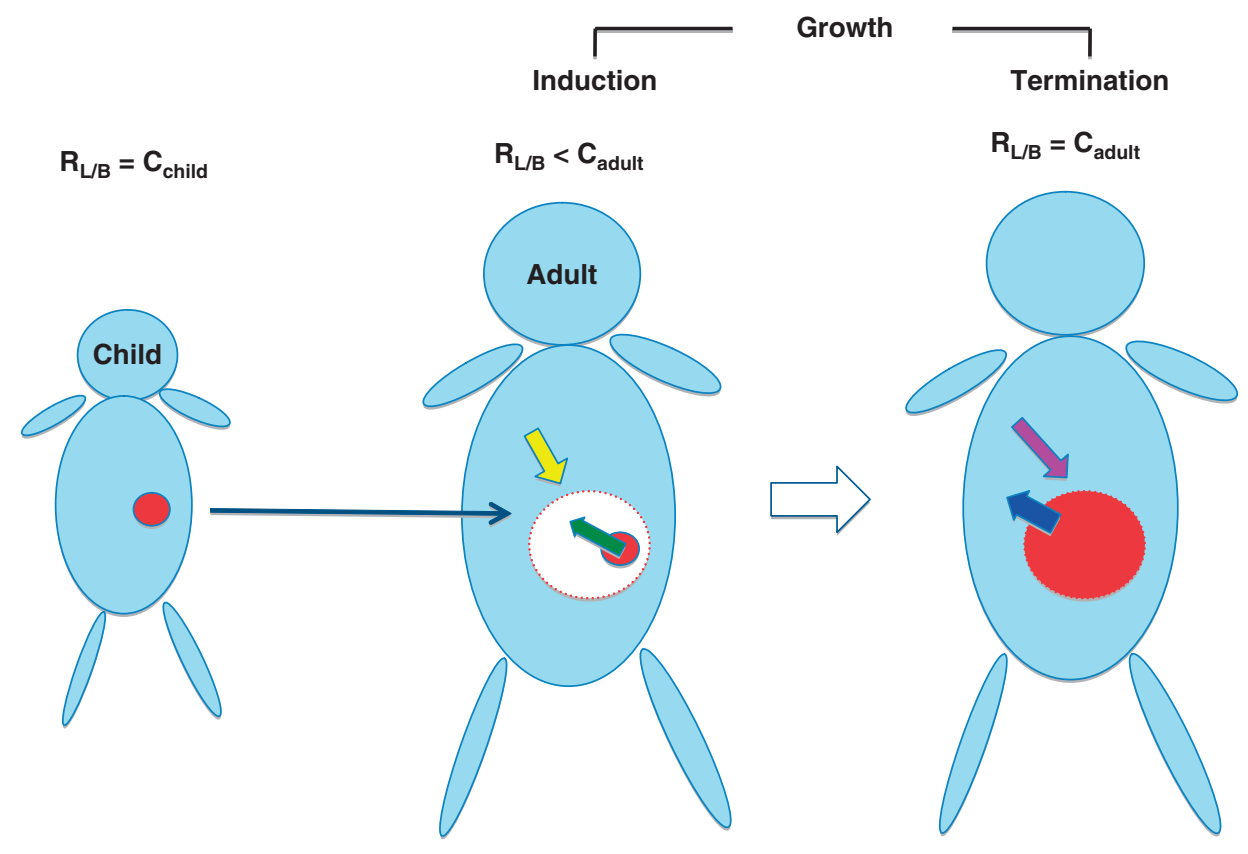

Figure 1: Small-for-size liver transplantation. The liver is removed from a child with $\mathrm{R}_{\mathrm{L} / \mathrm{B}}=\mathrm{C}_{\text {child }}$ $\left(\mathrm{R}_{\mathrm{L} / \mathrm{B}}\right.$ value of a child) and transplanted to the liver site of an adult with $\mathrm{R}_{\mathrm{L} / \mathrm{B}}=\mathrm{C}_{\text {adult }}$ whose liver has been removed due to liver failure. At the time of transplantation, $\mathrm{R}_{\mathrm{L} / \mathrm{B}}$ is less than $\mathrm{C}_{\mathrm{adult}}$, which triggers the generation of signals (yellow arrow) in the host body, which then induces signals (green arrow) in the transplanted liver. These mutual signalling molecules enforce the donor liver to grow until the $\mathrm{R}_{\mathrm{L} / \mathrm{B}}$ reaches $\mathrm{C}_{\text {adult }}$, which generates exchanges of new signals between the body (purple arrow) and liver (dark blue arrow) that lead the liver to terminate the growth. $\mathrm{R}_{\mathrm{L} / \mathrm{B}}$, the ratio of $\mathrm{W}_{\text {liver }}$ to $\mathrm{W}_{\text {body }}$.

liver transplant experiment using dogs. A similar size adjustment of transplanted livers to the recipient body size has been reported in rats [3].

These studies with humans, dogs and rats indicate that mammals possess an optimal $R_{L / B}$ value, quickly 'sense' any change in this value and initiate reactions to restore the correct $\mathrm{R}_{\mathrm{L} / \mathrm{B}}$. Liver size optimization may result from biochemical reactions induced by an $\mathrm{R}_{\mathrm{L} / \mathrm{B}}$ change that is associated with physiological conditions both within and outside the liver. Due to the central role of the liver in nutritive metabolism, changes in $\mathrm{R}_{\mathrm{L} / \mathrm{B}}$ most likely induce imbalances in homeostasis regulated by the liver and other parts of the body and, as a result, drive the remodelling of the liver to restore optimal $\mathrm{R}_{\mathrm{L} / \mathrm{B}}$. The mechanisms underlying the rule of liver weight optimization should also operate in liver organogenesis and regeneration to prevent hyperplasia.

In this review, we first briefly summarize the histological features of the mammalian liver, because the intercellular interactions among liver composite cells play critical roles in the liver weight optimization and these interactions are induced depending on the histological location. We then review the present status of the study of liver organogenesis and regeneration to see how the liver weight optimization is achieved in these biological processes. Third, we introduce a mouse with a liver whose parenchymal cells are largely replaced with human hepatocytes as a new experimental animal model for studying the liver weight optimization rule. Finally, we consider the possible significance of the liver weight optimization 
from a biotechnological point of view. We are much obliged to the recent reviews by Zaret [5] and Michalopoulos [6] on liver organogenesis and regeneration, respectively, for preparing the present review. This review appeared in the proceedings of WIT 2008 Conference in a condensed form.

\section{HISTOLOGICAL FEATURES OF THE MAMMALIAN LIVER}

Animal organs are generally composed of two types of cells, parenchymal and nonparenchymal [7]. The former are specialized to execute the functions of the organ, while the latter regulate the proliferation and function of the former. In the liver, the parenchymal cell is the hepatocyte, and the major nonparenchymal cells are the endothelial cells of hepatic blood vessels, bile duct biliary cells, and stellate and Kupffer cells in Disse's space, which is located between the hepatic plate and the sinusoids. The portal vein is the major import route for nutrients to the liver via the hepatic sinusoids from the small and most of the large intestine, spleen and pancreas. Substances such as nutrients and oxygen in sinusoids and secretions from hepatic plates are exchanged through Disse's space. Stellate cells surround hepatocytes and are located under sinusoidal cells, a major cell type that produces the extracellular matrix (ECM) [8]. Hepatocytes, endothelial cells and stellate cells are the major cells responsible for the regulation of $\mathrm{R}_{\mathrm{L} / \mathrm{B}}$, whose occupancy ratios in humans are 65,21 and $5.5 \%$, respectively [9].

The liver processes the nutrients from the gut and intestine into proteins, lipids and carbohydrates. It also has an endocrine function in secreting albumin (Alb), most coagulation factors, several plasma carrier proteins and lipids into the blood. The liver also synthesizes bile and secretes them into the digestive tract. These functions are associated with the liver's elaborate histological structure [10]. Hepatocytes are well organized in an aggregated association (the hepatic epithelium), in which hepatocytes polarize, creating a small apical domain that lines channels between cells (canaliculi) that connect to bile ducts and drain into the intestine. The basal layer are juxtaposed to a fenestrated endothelium that lines sinusoids or tissue gaps in which blood flows from the arterial and intestinal portal circulations to the venous circulation [6]. These histological features of the liver enable it to fulfill the requirements for body to maintain life and constitute the background for the liver weight optimization. In other words, various cells cooperatively work to optimize the liver weight, responding to the changes in the conditions of body.

\section{HEPATIC ORGANOGENESIS IN RELATION TO LIVER SIZE OPTIMIZATION RULE}

A mouse starts its life as an independent individual at birth that occurs around 21 days after gestation (E21). The liver organogenesis is complete before birth, at E17, when the embryonic hepatocytes develop into adult-type parenchymal cells, which is accompanied with the termination of hematopoietic functions of the liver and the commencement of the adult functions. To my knowledge, little is known as to the question whether the embryonic liver and the adult-type liver before birth develop following the liver weight optimization rule. Researchers paid most attention to the initial stages of development (liver bud formation and its specification to the liver) but much less attention to the mechanism by which late embryonic liver terminates the development that is deeply related to the thesis of this review. Despite this, we briefly summarize the current understanding of the molecular mechanism of liver organogenesis herein to make it clear that what should be studied for understanding the liver organogenesis from the viewpoint of liver size optimization.

3.1 Emergence of liver bud, the aggregates of bipotential hepatoblasts under the influence of various signalling molecules

The embryonic liver originates from the endoderm of an early embryo and develops through a series of interactions between endodermal and mesodermal cells in which a variety of genes are involved (Fig. 2). 


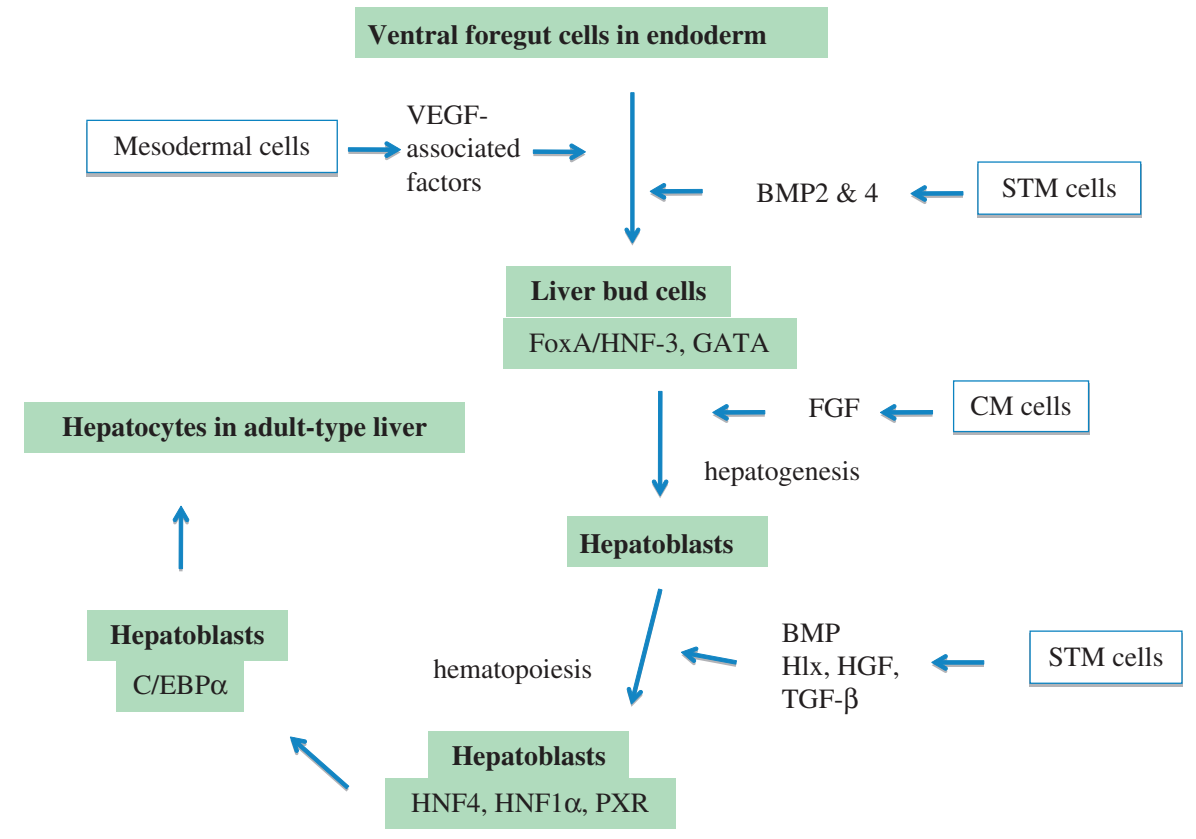

Figure 2: Major events in embryonic liver organogenesis. Ventral foregut cells transform to liver bud cells in which two types of molecules exert inductive actions, VEGF-associated factors from mesodermal cells and the others (BMP2 \& 4) from STM cells. The resulting liver bud cells express Fox/HNF-3 and GATA gene to which another mesodermal cells (CM cells) deliver inductive molecules (FGF), which starts the hepatogenesis and differentiate liver bud cells into hepatoblasts. STM cells transform the hepatoblasts to hematopoietic hepatoblasts by stimulating with BMP, Hlx and TGF- $\beta 1$. Then the hepatoblasts express HNF4, HNF1 $\alpha$ and PXR genes, and then $\mathrm{C} / \mathrm{EBP} \alpha$ gene, which leads to the formation of adult-type hepatocytes. The cells in the hepatocyte lineage are highlighted with the light green rectangle. BMP, bone morphogenetic proteins; CM, cardiogenic mesoderm; C/EBP $\alpha$, CCAAT/enhancer binding protein $\alpha$; FGF, fibroblast growth factor; FoxA, forkhead box A; HGF, hepatocyte growth factor; Hlx, H2.0-like homeobox gene; HNF-3, hepatocyte nuclear factor-3; PXR, pregnane X receptors; STM, septum transversum mesenchyme; TGF- $\beta$, transforming growth factor $\beta$; VEGF, vascular endotherial growth factor.

Endodermal cells in the ventral foregut differentiate into hepatoblasts, the progenitor population of both hepatocytes and biliary cells (cholangiocytes). This differentiation requires a series of inductive signals from at least two different mesodermal cell types, the septum transversum mesenchyme (STM) and the cardiogenic mesoderm (CM). Recently, other mesodermal cell type, endothelial cells that later form the blood vessels, has been reported as interactive cells with the STM and CM [5]. Among the ventral foregut endodermal cells, there are cells that are in a physically close apposition to the prospective STM cells that are secreting morphogenetic proteins [bone morphogenetic proteins (BMPs)] 2 and 4, members of the transforming growth factor $\beta$ (TGF- $\beta$ ) superfamily of paracrine signalling molecules [11]. These proteins easily reach the nearby endodermal cells and are caught by them through the corresponding receptors, resulting in the emergence of the BMP-stimulated cells. The stimulated cells in turn start to synthesize autocrine factors such as forkhead box A (FoxA) proteins [previously known as hepatocyte nuclear 
factor-3 (HNF-3) proteins] and GATA-binding transcription factors (GATA factors) [12]. These ventral foregut cells become competent to begin hepatogenesis [13].

Then the competent cells become hepatoblasts under the influence of fibroblast growth factor (FGF). The competent cells receive FGF from the nearby CM at E8.5 [14] through the tyrosine kinase FGF receptors and activate a series of intracellular signalling that results in the activation of liver-associated genes in their chromatins. The endoderm domain consisting of hepatoblasts is called the hepatic endoderm. The hepatic endoderm develops to form the liver bud during E8.5-E9.5 [15]. The initiation of the liver bud is thought to be intimately associated with its vascularization [16]. Thus, early endothelial cells appear to act as an early mesodermal inducer of liver, perhaps earlier than that from the STM $[5,17]$.

Then the liver bud grows into the STM during E9.5-E10.5 under the influence of BMP [18]. The growth of hepatoblasts are also stimulated by other STM-factors such as H2.0-like homeobox gene $(H l x)$ [19], hepatocyte growth factor (HGF) [20] and TGF- $\beta$ that activates Smad2 and Smad3 in the hepatic endoderm [21]. The enlargement of the liver bud is associated with the development of its vascularization, and the liver bud develops into a hematopoietic organ by E14.5.

3.2 Split of hepatic and biliary epithelial cell lineages in the liver bud under the influence of HNF, Foxf1 and Notch signalling

The bipotential hepatoblasts generate the hepatocyte and biliary epithelial cell lineages at $\sim$ E13.5 [22-24] in which HNF4 and HNF6 genes play the prime roles, respectively. HNF4 in hepatoblasts directly promotes hepatocyte gene expression and the formation of hepatocyte epithelial morphology [25]. When the gene for this protein is inactivated in mice, many mature hepatocyte genes encoding apolipoproteins, serum factors and metabolic enzymes are also inactivated. HNF4 controls the expression of at least two transcriptional regulators, $\mathrm{HNF} 1$ and pregnane $\mathrm{X}$ receptor (PXR), and elicits the terminal phase of hepatocyte differentiation [26]. Two HNF genes, HNF6 [27] and HNF1 $\beta$, are responsible for the biliary differentiation of hepatoblasts. These genes also positively control the later differentiation of biliary epithelia and the morphogenesis of bile ducts and of the gall bladder [5].

3.3 Construction of adult-type liver under the influence of $\mathrm{C} / \mathrm{EBP} \alpha$ signalling in relation to the liver weight optimization rule

The hepatocytes develop into adult-type parenchymal cells at E17 by constructing the adult liver plate. The plate contains the cell junctions that are required to create a polarized epithelium [28], where the apical cell surface is the site of bile secretion and the basal cell surface is apposed to the endothelial cells. The transcription factor C/EBP $\alpha$ (CCAAT/enhancer binding protein- $\alpha$ ) plays a central role in these processes by regulating many transcriptional gene cascades [29]. To our knowledge, no studies have measured $\mathrm{R}_{\mathrm{L} / \mathrm{B}}$ at the time of completion of liver organogenesis. Although liver construction is complete at E17, the embryo is still dependent on its mother, which raises a question. The liver weight optimization rule is empirically postulated for the adult-type liver, the liver owned by a vertebrate whose life is independent on mother. In this respect, it is intriguing to examine the change in $\mathrm{R}_{\mathrm{L} / \mathrm{B}}$ during liver regeneration after the partial hepatectomy (PHx) of the liver at E17-E21, when the liver construction has been completed, but the embryo is dependent on mother. The comparison of $\mathrm{R}_{\mathrm{L} / \mathrm{B}}$ at $\mathrm{E} 17$ with that of adult mice would be indicative of the biological significance of $\mathrm{R}_{\mathrm{L} / \mathrm{B}}$ and the functional status of the newly constructed liver in the whole system of the body at E17. It is also interesting to speculate that the genes working at the completion of liver organogenesis might also play critical roles in regulating $R_{\mathrm{L} / \mathrm{B}}$. 


\section{LIVER REGENERATION IN RELATION TO LIVER WEIGHT OPTIMIZATION RULE}

Liver failure stimulates the injured liver to recover its original mass, indicating that liver regeneration is a most appropriate phenomenon for studying the liver weight optimization rule. Liver regeneration studies have been usually undertaken with rats. Researchers surgically remove twothirds of the liver mass, which is referred to as a 2/3 PHx (2/3 PHx) rat model [30]. The $\mathrm{R}_{\mathrm{L} / \mathrm{B}}$ in this model is reduced to one-third of the normal rat $\mathrm{R}_{\mathrm{L} / \mathrm{B}}$, and the rat senses this reduction through a still unknown body system and then restores the original $\mathrm{R}_{\mathrm{L} / \mathrm{B}}$ (Fig. 3). The system should instantly recognize the change in $\mathrm{R}_{\mathrm{L} / \mathrm{B}}$ and respond immediately to the greater needs of body with liver loss. The liver is activated, starts the regeneration process as soon as $5 \mathrm{~min}$ after the loss and re-establishes the normal weight within 5-7 days [6]. The liver continues to reorganize lobular structures for several weeks until it re-establishes a liver histology indistinguishable from the original [31]. The restoration of the total cell number and mass of hepatocytes is an essential event of liver regeneration. Hepatocytes are the first cells to begin DNA synthesis at $12 \mathrm{~h}$ after PHx, with peak DNA synthesis at $24 \mathrm{~h}$, followed soon after by biliary epithelial cells and then endothelial cells, starting at 2-3 days and ending at about 4-5 days after PHx [6].

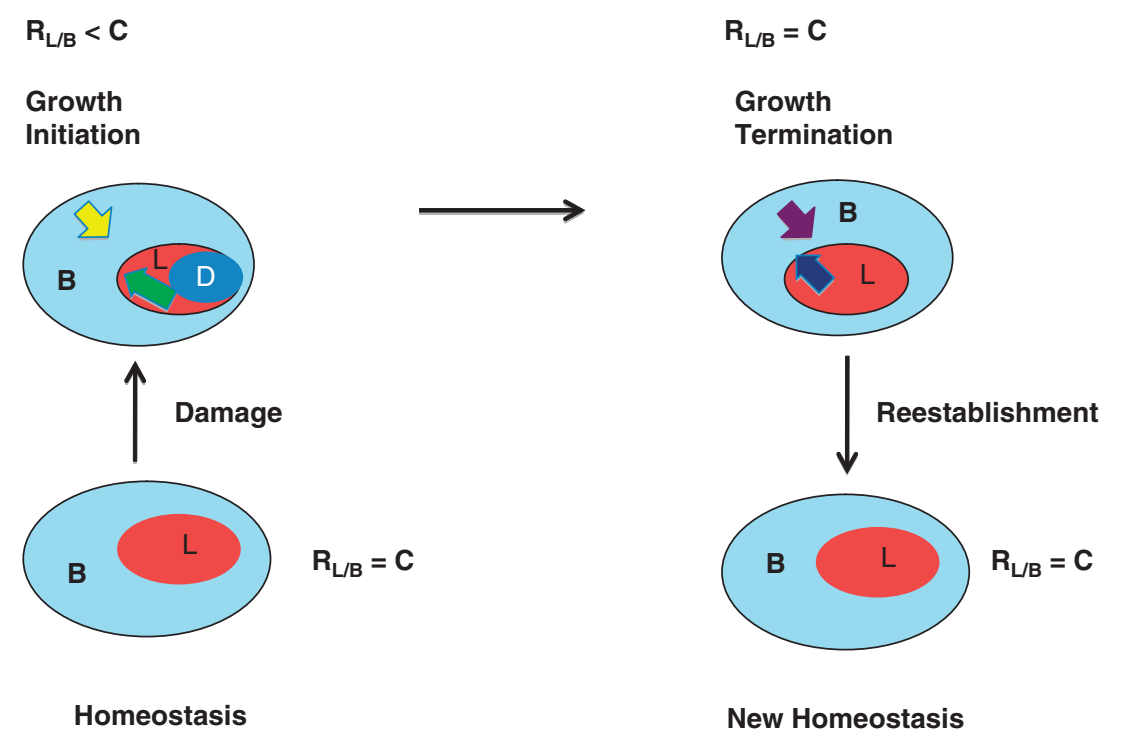

Figure 3: Conceptual scheme of liver regeneration. Initiation and termination of liver regeneration in response to the change in $R_{L / B}$. The liver in the homeostatic condition has its own $R_{L / B}$ value $(C)$. When it is injured, $R_{L / B}$ becomes less than $C$. The condition of $R_{L / B}<C$ generates changes in the quantities of metabolic parameters in the body, which triggers the interactions between the liver and the body. The signal from the body (yellow arrow) is delivered directly or indirectly through the nonparenchymal cells to the hepatocytes. In response to body signals, the damaged liver secretes molecules to the body (green arrow). These exchanges of the signalling molecules initiate liver regeneration and the liver grows, which increases $R_{L / B}$ to the original $C$ value. When $R_{L / B}$ reaches $C$, exchanges of new signals begin between the body (purple arrow) and the liver (dark blue arrow) that lead the liver to terminate the growth and to get into a new homeostasis. B, body; D, damaged region of liver; $\mathrm{L}$, liver; $\mathrm{R}_{\mathrm{L} / \mathrm{B}}$, the ratio of $\mathrm{W}_{\text {liver }}$ to $\mathrm{W}_{\text {body }}$. 
4.1 Possible factors comprising the sensing system of $\mathrm{R}_{\mathrm{L} / \mathrm{B}}$ change - nutrient overload and hypoxia

Hepatic blood flow patterns change greatly following 2/3 PHx [6]. The blood supply per unit of liver tissue through the portal vein triples, causing nutrient overloading and may also increase the availability per hepatocyte of growth factors and cytokines derived from the intestine and pancreas, such as insulin and epidermal growth factor, which appears to favor the induction of hepatocyte proliferation. Nutrient overload apparently functions as a sort of 'body signal' to increase the number of hepatocytes to the original level (Fig. 4). The liver also becomes hypoxic, as portal vein blood has a much lower oxygen concentration than arterial blood, in which the oxygen content is unchanged after hepatectomy [6]. The resulting changes in redox environments in the remnant tissues may trigger regeneration.

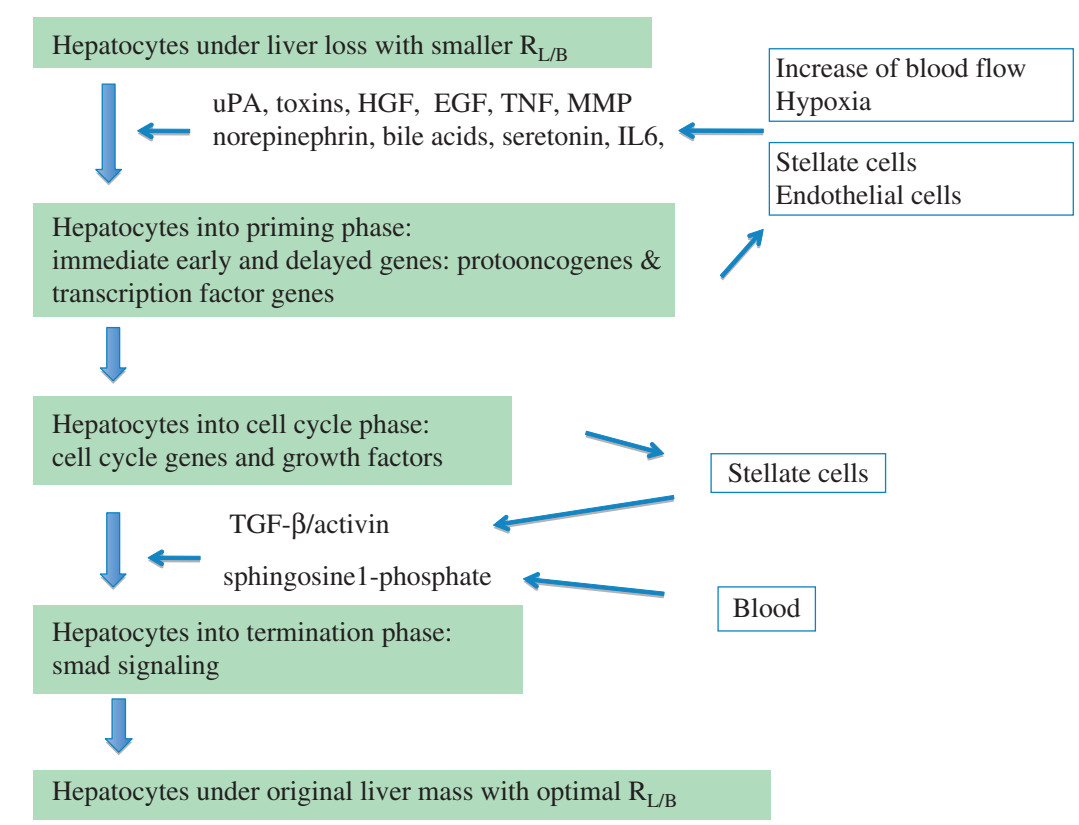

Figure 4: Outline of liver regeneration process. Hepatocytes with small $\mathrm{R}_{\mathrm{L} / \mathrm{B}}$ receive increased blood flow and become hypoxic. Stellate and endothelial cells are activated. These conditions increase the concentrations of uPA, toxins, etc. around the hepatocytes and bring the cells into the priming phase in which the hepatocytes express immediate early and delayed genes (protooncogenes and transcription factor genes). The hepatocytes then undergo the cell cycle phase. The activated stellate cells deliver TGF- $\beta$ /activin to the hepatocytes. Other factors such as sphingosine-1-phosphate also come from blood, which enforces the hepatocytes to move to the termination phase in which the cells activate the smad signalling. Finally, the hepatocytes reconstitute the liver with the original mass. The hepatocyte flow is indicated in light green color. EGF, epidermal growth factor; HGF, hepatocyte growth factor; IL, interleukin; MMP, matrix metalloproteinase; TGF, transforming growth factor; TNF, tumor necrosis factor; uPA, urokinase plasminogen activator. 
$4.2 \mathrm{R}_{\mathrm{L} / \mathrm{B}}$ sensing system at the cell level

The remnant liver regenerates under parenchymal to nonparenchymal signalling interactions (Fig. 4). The residual one-third of hepatocytes undergo one round of DNA synthesis, which peaks $24 \mathrm{~h}$ after surgery and increases their number to $60 \%$ of that required. A smaller percentage of cells enter a second round of DNA synthesis, which re-establishes the original number of hepatocytes [6]. Thus, the signalling interactions that initiate and terminate hepatocyte DNA synthesis and cell division are crucial players in the liver weight optimization process (Fig. 4). The optimization process from a smaller to the normal $\mathrm{R}_{\mathrm{L} / \mathrm{B}}$ is classified into four phases, the first three phases of which are usually distinguished in the regeneration process [32]: (1) priming phase (0-5 h after PHx), in which hepatocytes at the $\mathrm{G}_{0}$ phase of the cell cycle prepare to go through the G1 checkpoint to enter the G1 phase, (2) growth factor phase, in which hepatocytes are in the cell cycle and receive growth factor signals, (3) autonomous replication phase, in which hepatocytes divide autonomously without the help of growth factors and (4) termination phase, in which regeneration terminates, because the liver has regained its original $R_{L / B}$.

4.3 Initiation of hepatocyte DNA synthesis and division to restore the optimal $\mathrm{R}_{\mathrm{L} / \mathrm{B}}$ - the process regulated by multiple genes

A smaller $\mathrm{R}_{\mathrm{L} / \mathrm{B}}$ is immediately sensed by the body system as changes in the liver conditions such as nutrient overload and hypoxia, and rapidly induces more than 100 genes that are not expressed in the normal liver [33,34], but are related directly or indirectly to the events that prepare the hepatocytes to enter the cell cycle (priming phase) (Fig. 4). HGF appears to be the most important contributor to the initiation of regeneration [6]. The genes participating in the 'liver regeneration program' are divided into four groups based on the time of expression [32]: (1) immediate-early genes, (2) delayed genes, (3) cell cycle genes and (4) DNA replication and mitosis genes.

Hemodynamic changes induce increased urokinase plasminogen activator (uPA) activity [35] as early as 5 min after PHx [36], which is critical to initiate liver regeneration, as mice genetically deficient in urokinase show defective liver regeneration [37]. Then, urokinase activates matrix remodelling, which causes the release of locally bound growth factors and peptides such as HGF $[36,38]$. Tumor necrosis factor concentrations in the blood also increase very rapidly post-PHx [32] and may also play a role in matrix remodelling by inducing the expression of matrix metalloproteinase 9 , another important matrix remodeller required for liver regeneration, in hepatocytes [39] by $30 \mathrm{~min}$ post-PHx $[40,41]$.

HGF receptor, cMet, is activated within 30-60 min post-PHx in hepatocytes [42]. The establishment of HGF/cMet signalling is a critical key in initiating liver regeneration [43]. HGF is also produced by stellate [44] and hepatic endothelial cells [45] $3 \mathrm{~h}$ post-PHx. In turn, the activated hepatocytes produce growth factors, such as platelet-derived growth factor, that are mitogenic for stellate cells [46], as well as endothelial cell mitogens, such as vascular endothelial growth factor, FGF1 and FGF2 $[47,48]$. Such interactive cell activities enable the residual liver tissues to construct new networks of sinusoids and liver plates. In this way, hepatocytes and endothelial or stellate cells establish new networks of mutually assisted proliferation [6]. Varieties of other factors that regulate the initial phase of liver regeneration have been reported [6]. In response to these environmental changes induced by smaller $\mathrm{R}_{\mathrm{L} / \mathrm{B}}$, the hepatocytes begin to express immediate-early genes $1-2 \mathrm{~h}$ post-PHx without requiring the prior activation of specific proteins, in which protooncogenes (c-fos, c-jun and c-myc) and transcription factor genes (NFkB, AP-1, C/EBP $\alpha$ and STAT3) are included [6].

Although, as summarized above, the gene-regulation networks have been revealed in detail, we still lack knowledge about the mechanism that directly connects the $\mathrm{R}_{\mathrm{L} / \mathrm{B}}$-dependent environmental 
parameter changes and the regeneration program activation. The studies to reveal the molecular mechanism of liver regeneration from the viewpoint of the $\mathrm{R}_{\mathrm{L} / \mathrm{B}}$ optimization mostly remain to be explored.

4.4 Termination of regeneration to avoid abnormal increase of $\mathrm{R}_{\mathrm{L} / \mathrm{B}}-$ the process regulated by relatively simple gene networks

Regeneration should be terminated when the optimal $\mathrm{R}_{\mathrm{L} / \mathrm{B}}$ has been restored. Compared to the abovedescribed complex machinery for the initiation of regeneration, its termination seems to proceed through a simple mechanism. Only a few candidates, TGF- $\beta$ and activin, have been suggested as termination signalling molecules [6]. TGF- $\beta$ consists of three isoforms, TGF- $\beta 1$ to 3 , and is a multifunctional cytokine regulating cell development, growth and homeostasis in most tissues [49]. Experimental data have supported the idea that TGF- $\beta 1$ limits hepatocyte proliferation in the late phase of liver regeneration, as the liver approaches its original $\mathrm{R}_{\mathrm{L} / \mathrm{B}}$ and terminates regeneration [50]. Stellate cells are a major producer of TGF- $\beta 1$ [51], strongly suggesting the requirement of coordinated interactions between hepatocytes and stellate cells to terminate regeneration normally. Activin is also a mitoinhibitor of hepatocytes [52].

However, recent studies with mice genetically altered to control gene expressions in hepatocytes have not unequivocally supported the role of TGF- $\beta$ and activin as liver regeneration terminators. Transgenic mice overexpressing TGF- $\beta 1$ in the liver suppressed early DNA synthesis after PHx but terminated liver regeneration normally [53]. The livers of transgenic mice that overexpressed TGF- $\beta 1$ in hepatocytes regenerated almost normally, despite high TGF- $\beta 1$ levels in the liver and plasma [54]. Normal termination of liver regeneration was also reported in knockout (KO) mouse strains in which TGF- $\beta$ RII was eliminated [55]. In these transgenic mice, the TGF- $\beta$ RII gene (Tgf $\beta r 2)$ was knocked out of the liver (R2LivKO). As expected, the disruption of TGF- $\beta$ signalling in the liver enhanced the proliferative response of hepatocytes after PHx but, unexpectedly, did not affect the termination of liver regeneration. The KO-mice recovered liver mass more rapidly, with a significant increase in $\mathrm{R}_{\mathrm{L} / \mathrm{B}}$ at 96 and $120 \mathrm{~h}$ after PHx. However, there was no significant difference in liver mass between normal and KO mice after PHx. Activin-A signalling increased, and the Smad pathway, the intracellular signalling induced by activin A, was persistently active in the regenerating liver of the KO-mice. Blockage of activin-A signalling by follistatin, a specific inhibitor of activin A, resulted in slightly increased hepatocyte proliferation at $120 \mathrm{~h}$ over that in control animals but without a significant difference in $\mathrm{R}_{\mathrm{L} / \mathrm{B}}$. Thus, it is possible that neither TGF- $\beta$ nor activin is a major factor in hepatic regeneration.

Grady and colleagues [56] created a similar hepatocyte-specific Tgf $\beta r 2$-KO mouse called Alb-cre $T g f \beta r 2 \mathrm{flx} / \mathrm{flx}$. However, their conclusion about the role of TGF- $\beta$ signalling in the termination of liver regeneration differed from that obtained using R2LivKO mice. After 70\% PHx, hepatocyte proliferation and $\mathrm{R}_{\mathrm{L} / \mathrm{B}}$ increased in the Alb-cre $T g f \beta r 2 \mathrm{flx} / \mathrm{flx}$ mice compared to the $T g f \beta r 2 \mathrm{flx} / \mathrm{flx}$ control mice, which led them to conclude that TGF- $\beta$ signalling in vivo regulates the mitogenic response in the regenerating liver, thus affecting $\mathrm{R}_{\mathrm{L} / \mathrm{B}}$ after $\mathrm{PHx}$.

TGF- $\beta$ and activin intracellular signallings commonly use the Smad protein complex as an intracellular mediator from the cytokine receptors to chromosomal sites of target genes [57]. Ju et al. [58] engineered smad-KO mice with the following genotypes: Smad2 $2^{f f} \operatorname{Smad}^{++}$(normal control: Ctrl), Smad2 $2^{\text {ff }}$ Smad3 ${ }^{\text {dex8/dex8 }}$ (Smad3 knockout: S3KO), Albcre/Smad2fff Smad3 ${ }^{++}$(hepatocyte-specific Smad2 knockout: S2HeKO) and Albcre/Smad2fff Smad3 $3^{d e x 8 / d e x 8}$ (hepatocyte-specific Smad2/Smad3 double knockout: DKO). DKO mouse phenotypes are of particular interest. Both S2HeKO and DKO mice were viable and developed postnatal liver with normal morphology and functions for at least 8 months, indicating that Smad2 and Smad3 are not required for liver development. Hepatocytes isolated from $\mathrm{S} 2 \mathrm{HeKO}$ mice were transplanted into CCl4-injured mice. The repopulation rate 
increased dramatically in recipient livers compared to that in livers of mice transplanted with hepatocytes from control mice. However, the occupancy (repopulation rate) of $\mathrm{S} 2 \mathrm{HeKO}$ hepatocytes was quite low ( $\sim 3 \%$ at 3 months post-transplantation), and the changes in $\mathrm{R}_{\mathrm{L} / \mathrm{B}}$ were not described.

These 'loss of function' experiments failed to directly show the roles of TGF- $\beta$, activin and Smad protein signalling in the termination of liver regeneration. However, a number of other studies strongly suggest that this signalling plays at least a part as a mechanism underlying the liver weight optimization rule. Nevertheless, other molecules may be involved in terminating liver growth [6], such as G-protein-coupled endothelial differentiation gene and sphingosine-1-phosphate, which have antiproliferative effects during liver regeneration after PHx [59]. Whatever the mechanism, the regenerating liver correctly assesses the termination point of DNA replication that matches optimum $\mathrm{R}_{\mathrm{L} / \mathrm{B}}$, ensuring the correct liver weight, but not exceeding it [6]. A small wave of hepatocyte apoptosis has been reported at the end of regeneration [60], which suggests that the liver continues to grow past the original mass at the end of regeneration and that the excess is deleted by an apoptotic mechanism [6]. Even if this were the actual termination mechanism, the mechanism by which the regenerating liver recognizes the amount of excess is yet to be elucidated.

\section{LIVER REGENERATION BY TRANSPLANTED XENOGENIC HEPATOCYTES}

\subsection{A mouse bearing transplanted homogenic or xenogenic hepatocytes as a tool to study the} mechanism of liver weight optimization

As a third model for studying the mechanism of the liver weight optimization, we introduce a mouse in which the liver is injured and the hepatocytes are in situ replaceable with transplanted counterpart cells. Sandgren et al. [61] developed a model of liver regeneration in albumin promoter/enhancerdriven urokinase (Alb-uPA) gene transgenic $\left(\mathrm{Tg}_{\mathrm{Alb}-\mathrm{uPA}}\right)$ mice, in which the hepatocyte-targeted expression of the hepatotoxic transgene creates a functional liver deficit, thus generating a chronic stimulus condition for liver growth. This fact indicates that the $\mathrm{R}_{\mathrm{L} / \mathrm{B}}$ of the mouse is 'functionally' decreased, although it might be 'physically' much unchanged. In this mouse, when a hepatocyte stochastically deletes the deleterious transgene, the hepatocyte starts to replicate and selectively expands to regain the original functional $\mathrm{R}_{\mathrm{L} / \mathrm{B}}$ value. This event occurred most often in mice that are hemizygous for the transgene. In these animals, transgene expression in hepatocytes is abolished because of a DNA rearrangement that affects the transgene tandem array, permitting the individuals to survive beyond birth, with plasma uPA concentrations gradually returning to normal by 2 months of age. Transgene-deficient cells proliferate selectively, forming clonal colonies called hepatic nodules. These nodules expand, replacing the surrounding transgene-active cells that cannot replicate because of cellular damage, and eventually replace the entire liver. This study demonstrated that a $\operatorname{Tg}_{\text {Alb-uPA }}$ mouse is useful to examine the replicative capacity of not only mouse hepatocytes but also those of other mammals that can be managed to acquire immunotolerance [61].

Rhim et al. [62] introduced the Alb-uPA transgene into immunotolerant nu/nu mice by mating $\operatorname{Tg}_{\text {Alb-uPA }}$ mice with Swiss athymic nude $(n u / n u)$ mice, generating immunotolerant $\operatorname{Tg}_{\text {Alb-uPA }}$ mice $\left(\mathrm{Tg}_{\mathrm{Alb}-\mathrm{uPA}} / \mathrm{NUDE}\right.$ mice). Rat $(r)$ liver cells were transplanted into the livers of $\mathrm{Tg}_{\mathrm{Alb} \text {-uPA }}{ }^{+l+} / \mathrm{NUDE}$ mice that are homozygous for the transgene. The host livers that had not been transplanted with $r$-liver cells were completely pale (white) in color. In contrast, those with $r$-liver cells were composed of white and red regions, with white regions representing the area composed only of transgene-expressing host cells and red regions representing the area composed only of transgenedeleted host mouse $(m)$ cells or repopulated $r$-cells, or both. Immunohistochemical analysis with specific antibody against $r$-hepatocytes revealed that the red region was composed primarily of 
$r$-hepatocytes. Completely regenerated transgenic mouse livers resemble normal mouse livers in color, shape and size. Quantification of the Southern blot DNA bands demonstrated that up to 56\% of the DNA was of rat origin, which accords well with the parenchymal cell occupancy rate in the liver and strongly supports the idea that the host liver consists of $r$-parenchyma and $m$-nonparenchyma, including vessels, bile ducts and associated connective tissues. The $\mathrm{R}_{\mathrm{L} / \mathrm{B}}$ is $6.8 \%$, which is similar to that of nontransgenic control mice (5.8\%), indicating that $r$-hepatocytes in the rat and mouse $(r / m)$-chimeric livers composed of $r$-parenchyma and $m$-nonparenchymal cells are able to normally terminate growth. The successful generation of a healthy mouse with a chimeric liver indicates that $r$-parenchymal and $m$-nonparenchymal cells are able to communicate with each other to reconstitute a functional liver, despite the species difference.

As described previously, hepatocytes initiate and terminate proliferation under the influence of nonparenchymal cells. Thus, the normal proceeding and termination of $r / m$-chimeric liver regeneration implies that $r$-hepatocytes produce surface proteins that interact correctly with soluble $m$-factors, $m$-ECM and $m$-surface proteins on $m$-nonparenchymal cells. The successful replacement of $\mathrm{Tg}_{\mathrm{Alb}-\mathrm{uPA}}{ }^{+/+} / \mathrm{NUDE}$ mouse livers with $r$-hepatocytes raised the exciting possibility that they could also be reconstituted with human (h)-hepatocytes [62].

In light of the successful creation of a mouse bearing an $r / m$-chimeric liver, we may consider the biological significance of the $\mathrm{R}_{\mathrm{L} / \mathrm{B}}$ of mammals. One idea is that the $r$-hepatocyte has an inherent mechanism to memorize $r-\mathrm{R}_{\mathrm{L} / \mathrm{B}}$. Another interesting question is whether the $\mathrm{R}_{\mathrm{L} / \mathrm{B}}$ of the $r / m$-chimeric mouse is $r-\mathrm{R}_{\mathrm{L} / \mathrm{B}}$ or $m-\mathrm{R}_{\mathrm{L} / \mathrm{B}}$, but the similarity of $r-\mathrm{R}_{\mathrm{L} / \mathrm{B}}$ and $m-\mathrm{R}_{\mathrm{L} / \mathrm{B}}$ currently precludes an answer. At present, we support the idea that the 'demands' of the mouse body regulate gene expression associated with the initiation and termination of liver regeneration in both $r$-hepatocytes and $m$-nonparenchymal cells. Thus, we strongly suggest that $r$-hepatocytes stop proliferating when the liver mass adequate for the body demands of the mouse is acquired.

\subsection{Repopulation of $h$-hepatocytes in damaged mouse liver}

We generated a mouse whose liver is almost completely replaced with $h$-hepatocytes, thus creating a humanized or chimeric $(h / m)$ mouse [63]. A severe combined immunodeficient (SCID) mouse (mouse $_{\text {SCID }}$ ) was mated with $\mathrm{Tg}_{\text {Alb-uPA }}{ }^{+/+}$to yield liver-injured SCID mice (mouse Alb-uPA/SCID $_{\text {). }}$ ). $h$-hepatocytes were transplanted into the livers of these mice. The $h$-hepatocytes engrafted the liver at rates as high as $92 \%$ and progressively repopulated it. The expansion of $h$-hepatocyte colonies was visualized by immunohistological staining of liver sections with $h$-specific anti-CK8/18 antibodies. The $h$-hepatocytes started to proliferate at 7 days after transplantation. Their colonies gradually became larger and were almost confluent at around 70 days when the number ratio of $h$-hepatocytes to the total hepatocytes in the liver, replacement index (RI), reached as high as 96\%. The chimeric nature of the liver was clearly demonstrated immunohistochemically, in which liver sections were stained for type IV collagen, laminin, stabilin (a liver endothelial cell marker), BM8 (a Kupffer cell marker) and desmin (a hepatic stellate cell marker) (Fig. 5). These results clearly show that the mouse liver in chimeric mice with a high RI consists of parenchymal cells (mostly $h$-cells and a low percentage of $m$-cells), $m$-nonparenchymal cells and $m$-ECMs.

Cytochrome P450 (CYP) plays key roles in the metabolism of chemicals and medicines. We evaluated the functional normality of $h$-hepatocytes in mouse liver by comparing the expression profiles of mRNAs and proteins of $h$-CYP in the chimeric mouse liver and the donor liver and found that the expressions of six $h$-CYP (CYP1A1, 1A2, 2C9, 2C19, 2D6 and 3A4) mRNAs were similar to those of the donor liver [63]. This suggests that $h$-hepatocytes in the murine liver show the same spectrum of CYP gene expression as in the human body. In addition, the expression of these CYP genes is normally 

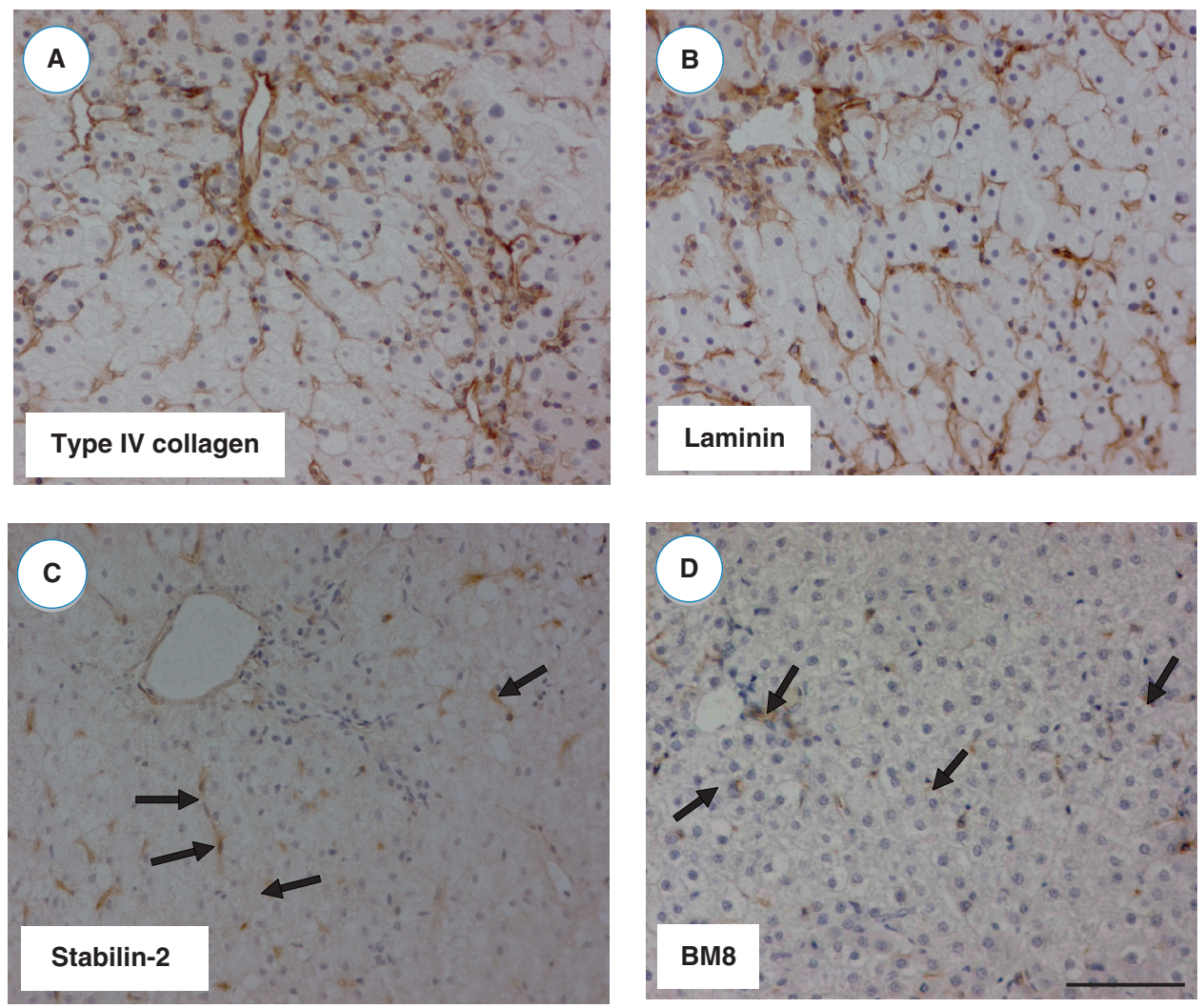

Figure 5: Immunohistochemistry of $h$-hepatocyte-chimeric mouse liver. The chimeric liver is composed of $h$-hepatocytes and $m$-nonparenchymal cells. UPA/SCID mice were transplanted with $h$-hepatocytes. Liver sections were prepared from $h$-hepatocyte colonies of the mice after the repopulation was completed. Sections were immunostained with $m$-specific antibodies with type IV collagen (A), laminin (B), stabilin-2 (C), a maker of liver endothelial cells and BM8 (D), a marker of Kupffer cells. Immunosignals are brown colored and the typical immunopositive cells are indicated by the arrows in (C) and (D). Bar represents $100 \mu \mathrm{m}$.

regulated by specific CYP-inducing chemicals such as CYP3A4 against rifampicin, and CYP1A1 and CYP1A2 against 3-methylcholanthrene [63], indicating that $h$-hepatocytes in the mouse liver retain the same specific responsiveness toward drugs as they do in the human liver. Thus, we concluded that $h$-hepatocytes are able to initiate regeneration in the injured mouse liver, terminate it when they have largely repopulated the liver and exhibit normal phenotypes, at least in the examined cases.

\subsection{Repopulation kinetics of $h$-hepatocytes in the mouse liver}

During the study of $h / m$-chimeric mice, we noticed that the liver size of mice with RI $>90 \%$ was much larger than that of the normal mouse liver (unpublished, Utoh et al.), which seemingly contravenes the liver weight optimization rule. Thus, we examined the repopulation kinetics of $h$-hepatocytes in the 
mouse $_{\text {Alb-uPA/SCID }}$ model, by comparison with $r$-hepatocytes in mouse that are able to normally repopulate the host liver as described above [62]. Although both hepatocytes showed a high bromodeoxyuridine (BrdU)-labelling index during the first 2 weeks post-transplantation, the $h$-hepatocytes formed colonies much slower than the $r$-hepatocytes [64]. The RI of the $h / m$ - and $r / m$-mice reached $86 \%$ at 8 weeks and $100 \%$ at 5 weeks post-transplantation of $h$ - and $r$-hepatocytes, respectively. Experiments to measure the BrdU-labelling index and RI during xenogenic hepatocyte repopulation clearly demonstrated that the repopulation kinetics of $h$-hepatocytes are different from those of $r$-hepatocytes. $r$-Hepatocytes rapidly proliferated, completed repopulation by as early as 4 weeks post-transplantation and terminated the replication when the normal mouse $\mathrm{R}_{\mathrm{L} / \mathrm{B}}$ was attained. In contrast, $h$-hepatocytes proliferated slowly for a longer period and the $h / m$-chimeric liver continued to grow beyond the normal $m$-liver size. We showed that the $\mathrm{R}_{\mathrm{L} / \mathrm{B}}$ of chimeric mice was $>3$-fold than normal mice (manuscript in preparation, Utoh et al.).

The difference in replacement kinetics between $r$ - and $h$-hepatocytes may be attributable to the extent of taxonomic remoteness between the two. The environment within the host liver generated by $m$-nonparenchymal cells apparently met the requirements of $r$-hepatocytes for the normal initiation and termination of proliferation as those in the rat liver. However, the differences between mice and humans appear to be too great for liver cells to normally exchange the signals necessary for $h$-hepatocytes to normally initiate and terminate the proliferation. As shown in Fig. 4 , the crosstalk between hepatocytes and stellate cells are vitally important for the termination of hepatocyte growth. Immunohistochemistry demonstrated that $h$-hepatocytes are seemingly quite normally apposed with $m$-stellate cells (Fig. 6). But, $h$-hepatocytes and $m$-nonparenchymal cells do not appear to communicate to terminate it at the correct time, i.e. the time when the $\mathrm{R}_{\mathrm{L} / \mathrm{B}}$ regains the original value (Fig. 7). Or, there is the possibility that $h$-hepatocytes may not be able to change their inherent replication kinetics and autonomously determine proliferation speed independent of their host environments. From these studies of chimeric mice bearing xenogenic hepatocytes, we conclude that concordant

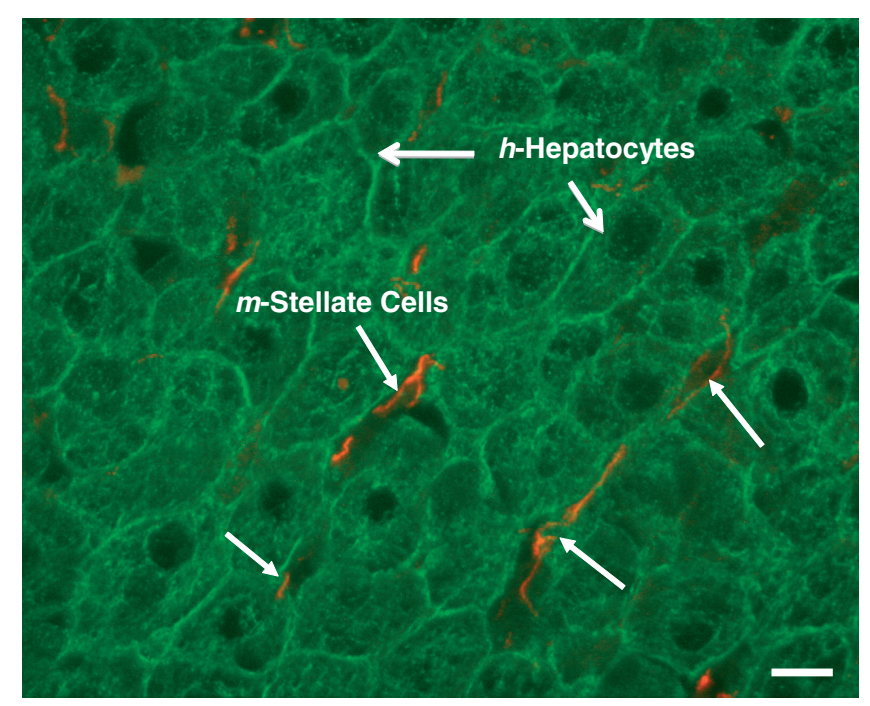

Figure 6: Close apposition of $m$-stellate cells around $h$-hepatocytes in the chimeric liver. A serial section shown in Fig. 5 was doubly stained with $h$-CK8/18 (green) for localizing $h$-hepatocytes and $m$-desmin (red) for $m$-stellate cells. $h$-Hepatocytes are closely apposed with $m$-stellate cells in Disse's space. Bar represents $10 \mu \mathrm{m}$. 


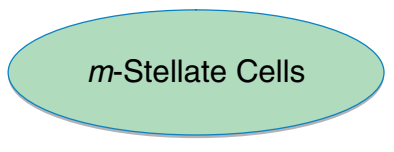

TGF- $\beta$

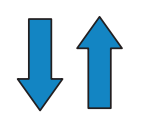

TGF $\beta R$

$m$ - or $r$-Hepatocytes

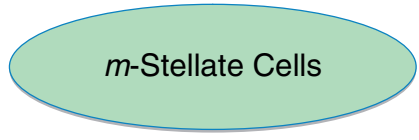

$\mathbf{R}_{\mathrm{L} / \mathrm{B}}<\mathrm{C}$

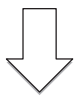

$\mathbf{R}_{\mathrm{L} / \mathrm{B}}=\mathbf{C}$

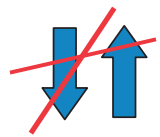

TGF $\beta R$

$h$-Hepatocytes

Figure 7: Liver growth termination signalling between hepatocytes and stellate cells. The liver is under regeneration when $R_{L / B}$ is $<$ its original value $(C)$. When the $R_{L / B}$ reaches $C$, crosstalk starts between stellate cells and hepatocytes, which causes stellate cells to express a hepatocyte-proliferation-termination signal(s) such as TGF- $\beta$ in a uPA/SCID mouse model bearing $m$ - or $r$-hepatocytes, but not $h$-hepatocytes, although $h$-hepatocytes express its receptor. $\mathrm{R}_{\mathrm{L} / \mathrm{B}}$, the ratio of $\mathrm{W}_{\text {liver }}$ to $\mathrm{W}_{\text {body }}$; TGF, transforming growth factor; TGFR, transforming growth factor receptor.

xenogenic hepatocytes ( $r$-hepatocytes) are able to adapt to mouse liver environments, where they are accepted as ' $m$-hepatocytes' by $m$-nonparenchymal cells. However, disconcordant hepatocytes $(h$-hepatocytes) cannot fully adapt to such environments. They can replicate, suggesting that signalling molecules from the surrounding $m$-nonparenchymal cells are functional in initiating DNA synthesis, cell division cycling. But signalling for terminating the hepatocyte replication is not adequate. These findings encourage us to use $\mathrm{h} / \mathrm{m}$-chimeric mice to study the molecular and cellular mechanism underlying optimization of $\mathrm{R}_{\mathrm{L} / \mathrm{B}}$, in which we could identify the molecule(s) that enables the $h$-hepatocyte chimeric mouse to correctly terminate the repopulation when $\mathrm{R}_{\mathrm{L} / \mathrm{B}}$ increases to the optimal value.

\section{CONCLUSIONS: BIOLOGICAL AND BIOTECHNOLOGICAL SIGNIFICANCE OF LIVER WEIGHT OPTIMIZATION RULE}

We have compared the essential processes of liver construction in embryonic organogenesis and adult regeneration with respect to the major genes and proteins that participate and regulate the processes as an approach for understanding the mechanism underlying the liver weight optimization rule. These two liver construction processes usually consist of two essential elements: principal cells and supporting cells that communicate with the principal cells and regulate their proliferation. The principal cells in both types of liver construction are hepatocytes. However, hepatocytes are not available at the beginning of organogenetic liver construction but available in the process of regenerative liver construction. Thus, the process by which hepatocytes are generated is also a part of the organogenesis program. The differentiation of endodermal cells to hepatocytes is the major process in liver construction during embryonic development in which inductive crosstalks between endodermal and mesodermal cells take place actively and consecutively. In contrast to the abundant information 
concerning the molecular events taking place in the initiation of liver organogenesis, as reviewed herein, little information is currently available about the molecular mechanism of the termination of liver organogenesis and about the timing when the liver starts to obey the liver weight optimization rule. Study on liver organogenesis is still fresh and challenging from the point of view of $R_{L / B}$ optimization, asking, for example, how do the liver cells perceive environmental requirements in an embryo and terminate organogenesis with correct $\mathrm{R}_{\mathrm{L} / \mathrm{B}}$ ? What is the relationship of a hypothetical gene signalling of termination with the $\mathrm{C} / \mathrm{EBP} \alpha$-regulated gene cascades responsible for the development of embryonic hepatocytes to adult-type parenchymal cells?

When the liver loses mass by PHx, it senses the reduction of $\mathrm{R}_{\mathrm{L} / \mathrm{B}}$ and activates the liver regeneration gene program, which instructs hepatocytes to initiate and later terminate DNA synthesis and division. Nutrient overloading and the reduced oxygen concentration per hepatocyte in the remnant liver may be the major chemical mediator for the body system that senses the change in $\mathrm{R}_{\mathrm{L} / \mathrm{B}}$. The new environments created by the loss of mass generate a series of signalling between hepatocytes and nonparenchymal cells that directs hepatocytes at $\mathrm{G}_{0}$ to enter the cell cycle. When the original liver mass has been restored, growth factor signalling, most likely TGF- $\beta$ /TGF- $\beta$ RII and activin/ ACVRII, is established between hepatocytes and stellate cells, thus terminating regeneration.

Termination has been relatively well studied in the context of the liver regeneration program but poorly understood in the context of the organogenesis program. An intriguing question is whether TGF- $\beta$ /TGF- $\beta$ RII and activin/ACVRII signalling are at work in the final process of liver organogenesis. At the completion of the liver organogenesis program, liver mass may be established according to the liver weight optimization rule for the individual body, and $\mathrm{R}_{\mathrm{L} / \mathrm{B}}$ may continue to increase to meet the growth of the body, generating a relatively stable $\mathrm{R}_{\mathrm{L} / \mathrm{B}}$ when the body mass reaches a plateau. We are far from understating the molecular mechanism underlying the liver weight optimization rule. In this review, we have shown that $\mathrm{R}_{\mathrm{L} / \mathrm{B}}$ is not simply a morphometric parameter but is in fact a metabolic parameter, reflecting the balance between bodily needs and the supply of nutrients and energy. Thus, the mechanism underlying the liver weight optimization rule appears to be highly complex, and its elucidation will be challenging.

Chimeric mice with disconcordant xenogenic livers constitute a better liver regeneration model to investigate the mechanism by which $\mathrm{R}_{\mathrm{L} / \mathrm{B}}$ is 'functionally' determined. Current data strongly suggest that the initiation of xenogenic hepatocyte DNA synthesis takes place relatively normally, compared to the normal host hepatocytes of the mice. However, DNA synthesis does not appear to terminate normally, probably because of the lack of signalling between hepatocytes and nonparenchymal cells. If we can clarify experimentally which signalling is missing and how this can be corrected, we will contribute greatly to understand both the complex mechanisms of liver weight adjustment and the mechanism by which biological rules are generated to harmonize life with its environment.

Liver regeneration has been attracting researchers from the viewpoints of both basic and applied sciences. In this review, we showed the usefulness of a $\mathrm{h} / \mathrm{m}$-chimeric mouse for studying liver regeneration, especially for studying the mechanism of regeneration termination in relation to the liver weight optimization rule, because this animal allows the liver to grow not following the rule. TGF- $\beta$ / activin signalling between hepatocytes and stellate cells appears to be essential in the optimization rule. However, the direct parameters in the rule should be related to nutritional imbalances caused by liver failure. There is still a big lack of knowledge on the relationship between TGF- $\beta$ /activin signalling and nutritional imbalances. Our $\mathrm{h} / \mathrm{m}$-chimeric mouse will contribute to fill the gap. Comprehensive understanding of the mechanism underlying the rule at the cellular and molecular levels will undoubtedly provide us an ideal type of artificial liver for liver-damaged patients that incorporates not only hepatocytes but also nonparenchymal cells necessary for sensing varieties of factors involved in the liver weight optimization rule. 


\section{ACKNOWLEDGEMENTS}

We are indebted to the excellent and comprehensive reviews by Dr. Kenneth S. Zaret and Dr. George $\mathrm{K}$. Michalopoulos of the current status of liver organogenesis and regeneration studies, respectively. We thank Ms. Tomomi Shimizu for assistance in preparing the manuscript. We thank Dr. A. Miyajima for kindly permitting us to present Figure 5C in which stabillin II antibodies were provided by him. Our study of chimeric mice with livers composed of human and rat hepatocytes was supported by the joint program of the Yoshizato Project in Cooperative Link of Unique Science and Technology for Economy Revitalization (CLUSTER) of the Japanese Ministry of Education, Culture, Sports, Science and Technology and Hiroshima Prefecture and Hiroshima University 21st Century COE Program for Advanced Radiation Casualty Medicine. Figures 5 and 6 were presented in PPAR Research (on line journal), vol. 2009, Article ID 476217, doi:10.1155/2009/476217 and used herein with the Publisher's permission. Descriptions about mice bearing homogenic and xenogenic hepatocytes were also presented in Expert Opin. Drug Metab. Toxicol. (2009) 5 (12):1-12 and PPAR Research (on line journal), vol. 2009, Article ID 476217, doi:10.1155/2009/476217 and some of the descriptions herein are cited from these publications with the Publisher's permission.

\section{REFERENCES}

[1] Van Thiel, D.H., Gavaler, J.S., Kam, I., Francavilla, A., Polimeno, L., Schade, R.R., Smith, J., Diven, W., Pencrot, R.J. \& Stazl, T.E., Rapid growth of an intact human liver transplanted into a recipient larger than the donor. Gastroenterology, 93, pp. 1414-1419, 1987.

[2] Kam, I., Lynch, S., Svanas, G., Todo, S., Polimeno, L., Francavilla, A., Penkrot, R.J., Takaya, S., Ericzon, B.G., Starzl, T.E. \& Van Thiel, D.H., Evidence that host size determines liver size: studies in dogs receiving orthotopic liver transplants. Hepatology, 7, pp. 362-366, 1987. doi:10.1002/hep.1840070225

[3] Francavilla, A., Zeng, Q., Polimeno, L., Carr, B.I., Sun, D., Porter, K.A., Van Thiel, D.H. \& Starzl, T.E., Small-for-size liver transplantation into large recipient: a model of hepatic regeneration. Hepatology, 19, pp. 210-216, 1994. doi:10.1002/hep.1840190131

[4] Stahl, W.R., Organ weights in primates and other mammals. Science, 150, pp. 1039-1042, 1965. doi:10.1126/science.150.3699.1039

[5] Zaret, K.S., Regulatory phases of early liver development: paradigms of organogenesis. Nature Reviews Genetics, 3, pp. 499-512, 2002. doi:10.1038/nrg837

[6] Michalopoulos, G.K., Liver regeneration. Journal of Cellular Physiology, 213, pp. 286-300, 2007. doi:10.1002/jcp.21172

[7] Yoshizato, K., Molecular mechanism and evolutional significance of epithelial-mesenchymal interactions in the body- and tail-dependent metamorphic transformation of anuran larval skin. International Review of Cytology, 260, pp. 213-260, 2007. doi:10.1016/S0074-7696(06)60005-3

[8] Nakatani, K., Okuyama, H., Himahara, Y., Saeki, S., Dong-Ho Kim, Nakajima, Y., Seki, S., Kawada, N. \& Yoshizato, K., Cytoglobin/STAP, its unique localization in splanchnic fibroblastlike cells and function in organ fibrogenesis. Laboratory Investigations, 84, pp. 91-101, 2004. doi:10.1038/sj.labinvest.3700013

[9] Pertoft, H. \& Smedsrød, B., Separation and characterization of liver cells. Cell Separation: Methods and Selected Applications, Vol. 4, eds T.G. Pretlow \& T.P. Pretlow, Academic Press: New York, pp. 1-24, 1982.

[10] Lemaigre, F. \& Zaret, K.S., Liver development update: new embryo models, cell lineage control, and morphogenesis. Current Opinion in Genetics \& Development, 14, pp. 582-590, 2004. doi:10.1016/j.gde.2004.08.004 
[11] Jones, C.M., Lyons, K.M. \& Hogan, B.L.M., Involvement of bone morphogenetic protein-4 (BMP-4) and Vgr-1 in morphogenesis and neurogenesis in the mouse. Development, 111, pp. 531-542, 1991.

[12] Kaestner, K.H., The making of the liver: developmental competence in foregut endoderm and induction of the hepatogenic program. Cell Cycle, 4, pp. 1146-1148, 2005.

[13] Smith, W.C. \& Harland, R.M., Expression cloning of noggin, a new dorsalizing factor localized to the Spemann organizer in Xenopus embryos. Cell, 70, pp. 829-840, 1992. doi:10.1016/0092$\underline{8674(92) 90316-5}$

[14] Jung, J., Zheng, M., Goldfarb, M. \& Zaret, K.S., Initiation of mammalian liver development from endoderm by fibroblast growth factors. Science, 284, pp. 1998-2003, 1999. doi:10.1126/ science.284.5422.1998

[15] Le Douarin, N.M., An experimental analysis of liver development. Medicine and Biology, 53, pp. 427-455, 1975.

[16] Millauer, B., Wizigmann-Voos, S., Schnürch, H., Martinez, R., Møller, N.P., Risau, W. \& Ullrich, A., High affinity VEGF binding and developmental expression suggest Flk-1 as a major regulator of vasculogenesis and angiogenesis. Cell, 72, pp. 835-846, 1993. doi:10.1016/0092$\underline{8674(93) 90573-9}$

[17] Matsumoto, K., Yoshitomi, H., Rossant, J. \& Zaret, K.S., Liver organogenesis promoted by endothelial cells prior to vascular function. Science, 294, pp. 559-563, 2001. doi:10.1126/ $\underline{\text { science. } 1063889}$

[18] Rossi, J.M., Dunn, N.R., Hogan, B.L.M. \& Zaret, K.S., Distinct mesodermal signals, including BMPs from the septum transversum mesenchyme, are required in combination for hepatogenesis from the endoderm. Genes \& Development, 15, pp. 1998-2009, 2001. doi:10.1101/ gad. 904601

[19] Hentsch, B., Lyons, I., Li, R., Hartley, L., Lints, T.J., Adams, J.M. \& Harvey, R.P., Hlx homeo box gene is essential for an inductive tissue interaction that drives expansion of embryonic liver and gut. Genes \& Development, 10, pp. 70-79, 1996. doi:10.1101/gad.10.1.70

[20] Schmidt, C., Bladt, F., Goedecke, S., Brinkmann, V., Zschiesche, W., Sharpe, M., Gherardi, E. \& Birchmeier, C., Scatter factor/hepatocyte growth factor is essential for liver development. Nature, 373, pp. 699-702, 1995. doi:10.1038/373699a0

[21] Weinstein, M., Monga, S.P., Liu, Y., Brodie, S.G., Tang, Y., Li, C., Mishra, L. \& Deng, C.X., Smad proteins and hepatocyte growth factor control parallel regulatory pathways that converge on $\beta 1$-integrin to promote normal liver development. Molecular and Cellular Biology, 21, pp. 5122-5131, 2001. doi:10.1128/MCB.21.15.5122-5131.2001

[22] Shiojiri, N., Analysis of differentiation of hepatocytes and bile duct cells in developing mouse liver by albumin immunofluorescence. Development, Growth \& Differentiation, 26, pp. 555-561, 1984. doi:10.1111/j.1440-169X.1984.00555.X

[23] Germain, L., Blouin, M.J. \& Marceau, N., Biliary epithelial and hepatocytic cell lineage relationships in embryonic rat liver as determined by the differential expression of cytokeratins, $\alpha$-fetoprotein, albumin, and cell surface exposed components. Cancer Research, $\mathbf{4 8}$, pp. 4909-4918, 1988.

[24] Spagnoli, F.M., Amicone, L., Tripodi, M. \& Weiss, M.C., Identification of a bipotential precursor cell in hepatic cell lines derived from transgenic mice expressing cyto-Met in the liver. Journal of Cell Biology, 143, pp. 1101-1112, 1998. doi:10.1083/jcb.143.4.1101

[25] Li, J., Ning, G. \& Duncan, S.A., Mammalian hepatocyte differentiation requires the transcription factor HNF-4 $\alpha$. Genes \& Development, 14, pp. 464-474, 2000. 
[26] Kuo, C.J., Conley, P.B., Chen, L., Sladek, F.M., Darnell, J.E., Jr., \& Crabtree, G.R., A transcriptional hierarchy involved in mammalian cell-type specification. Nature, 355, pp. 457-461, 1992. doi: $10.1038 / 355457 \mathrm{a} 0$

[27] Clotman, F., Lannoy, V.J., Reber, M., Cereghini, S., Cassiman, D., Jacquemin, P., Roskams, T., Rousseau, G.G. \& Lemaigre, F.P. The one-cut transcription factor HNF6 is required for normal development of the biliary tract. Development, 129, pp. 1819-1828, 2002.

[28] Stamatoglou, S.C. \& Hughes, R.C., Cell adhesion molecules in liver function and pattern formation. FASEB Journal, 8, pp. 420-427, 1994.

[29] Wang, N.D., Finegold, M.J., Bradley, A., Ou, C.N., Abdelsayed, S.V., Wilde, M.D., Taylor, L.R., Wilson, D.R. \& Darlington, G.J., Impaired energy homeostasis in C/EBP $\alpha$ knockout mice. Science, 269, pp. 1108-1112, 1995. doi:10.1126/science.7652557

[30] Higgins, G.M. \& Anderson, R.M., Experimental pathology of the liver, 1: Restoration of the liver of the white rat following partial surgical removal, Archives of Pathology, 12, pp. 186-202, 1931.

[31] Wagenaar, G.T., Chamuleau, R.A., Pool, C.W., de Haan, J.G., Maas, M.A., Korfage, H.A. \& Lamers, W.H., Distribution and activity of glutamine synthase and carbamoylphosphate synthase upon enlargement of the liver lobule by repeated partial hepatectomies, Journal of Hepatology, 17, pp. 397-407, 1993. doi:10.1016/S0168-8278(05)80224-7

[32] Fausto, N., Liver regeneration, Journal of Hepatology, 32, pp. 19-31, 2001. doi:10.1016/ $\underline{\mathrm{S} 0168-8278(00) 80412-2}$

[33] Taub, R., Liver regeneration 4: Transcriptional control of liver regeneration, FASEB Journal, 10, pp. 413-427, 1996.

[34] Taub, R., Liver regeneration: From myth to mechanism, Nature Reviews Molecular Cell Biology, 5, pp. 836-847, 2004. doi:10.1038/nrm1489

[35] Sokabe, T., Yamamoto, K., Ohura, N., Nakatsuka, H., Qin, K., Obi, S., Kamiya, A. \& Ando, J., Differential regulation of urokinase-type plasminogen activator expression by fluid shear stress in human coronary artery endothelial cells, American Journal of Physiology, 287, pp. H2027-2034, 2004.

[36] Mars, W.M., Liu, M.L., Kitson, R.P., Goldfarb, R.H., Gabauer, M.K. \& Michalopoulos, G.K., Immediate early detection of urokinase receptor after partial hepatectomy and its implications for initiation of liver regeneration. Hepatology, 21, pp. 1695-1701, 1995.

[37] Roselli, H.T., Su, M., Washington, K., Kerins, D.M., Vaughan, D.E. \& Russell, W.E., Liver regeneration is transiently impaired in urokinase-deficient mice. American Journal of Physiology, 275, pp. G1472-1479, 1998.

[38] Masumoto, A. \& Yamamoto, N., Stimulation of DNA synthesis in hepatocytes by hepatocyte growth factor bound to extracellular matrix. Biochemical and Biophysical Research Communications, 191, pp. 1218-1223, 1993. doi:10.1006/bbrc.1993.1347

[39] Haruyama, T, Ajioka, I, Akaike, T. \& Watanabe, Y., Regulation and significance of hepatocyte derived matrix metalloproteinases in liver remodeling. Biochemical and Biophysical Research Communications, 272, pp. 681-686, 2000. doi:10.1006/bbrc.2000.2837

[40] Kim, T.H., Mars, W.M., Stolz, D.B. \& Michalopoulos, G.K., Expression and activation of proMMP-2 and pro-MMP-9 during rat liver regeneration. Hepatology, 31, pp. 75-82, 2000. doi:10.1002/hep.510310114

[41] Olle, E.W., Ren, X., McClintock, S.D., Warner, R.L., Deogracias, M.P., Johnson, K.J. \& Colletti, L.M., Matrix metalloproteinase- 9 is an important factor in hepatic regeneration after partial hepatectomy in mice. Hepatology, 44, pp. 540-549, 2006. doi:10.1002/hep.21314 
[42] Stolz, D.B., Mars, W.M., Petersen, B.E., Kim, T.H. \& Michalopoulos, G.K., Growth factor signal transduction immediately after two-thirds partial hepatectomy in the rat. Cancer Research, 59, pp. 3954-3960, 1999.

[43] Paranjpe, S., Bowen, W.C., Bell, A.W., Nejak-Bowen, K., Luo, J.H. \& Michalopoulos, G.K., Cell cycle effects resulting from inhibition of hepatocyte growth factor and its receptor cMet in regenerating rat livers by RNA interference. Hepatology, 45, pp. 1471-1477, 2007. doi:10.1002/hep. 21570

[44] Schirmacher, P., Geerts, A., Jung, W., Pietrangelo, A., Rogler, C.E. \& Dienes, H.P., The role of Ito cells in the biosynthesis of HGF-SF in the liver. Hepatocyte Growth Factor (HGF-SF) and the cMet Receptor, eds I.D. Goldberg \& E.M. Rosen, Birkhäuser Verlag: Basel, pp. 285-299, 1993.

[45] LeCouter, J., Moritz, D.R., Li, B., Phillips, G.L., Liang, X.H., Gerber, H.P., Hillan, K.J. \& Ferrara, N., Angiogenesis-independent endothelial protection of liver: Role of VEGFR-1. Science, 299, pp. 890-893, 2003. doi:10.1126/science.1079562

[46] Pinzani, M., PDGF and signal transduction in hepatic stellate cells. Frontiers of Bioscience, 7 , pp. 1720-1726, 2002. doi:10.2741/pinzani

[47] Ross, M.A., Sander, C.M., Kleeb, T.B., Watkins, S.C. \& Stolz, D.B. Spatiotemporal expression of angiogenesis growth factor receptors during the revascularization of regenerating rat liver. Hepatology, 34, pp. 1135-1148, 2001. doi:10.1053/jhep.2001.29624

[48] Yu, C., Wang, F., Jin, C., Huang, X., Miller, D.L., Basilico, C. \& McKeehan, W.L. Role of fibroblast growth factor type 1 and 2 in carbon tetrachloride-induced hepatic injury and fibrogenesis. American Journal of Pathology, 163, pp. 1653-1662, 2003.

[49] Roberts, A.B. \& Sporn, M.B., Peptide growth factors and their receptors. The Transforming Growth Factors. Handbook of Experimental Pharmacology, Vol. 95, Part I, eds M.B. Sporn \& A.B. Roberts, Springer-Verlag: Berlin, pp. 419-472, 1990.

[50] Fausto, N., Mead, J.E., Gruppuso, P.A. \& Braun, L., TGF- $\beta$ in liver development, regeneration, and carcinogenesis. Annals of the New York Academy of Science, 593, pp. 231-242, 1990. doi:10.1111/j.1749-6632.1990.tb16115.x

[51] Ikeda, H., Nagoshi, S., Ohno, A., Yanase, M., Maekawa, H. \& Fujiwara, K., Activated rat stellate cells express c-met and respond to hepatocyte growth factor to enhance transforming growth factor $\beta 1$ expression and DNA synthesis. Biochemical and Biophysical Research Communications, 250, pp. 769-775, 1998. doi:10.1006/bbrc.1998.9387

[52] Ho, J., de Guise, C., Kim, C., Lemay, S., Wang, X.F. \& Lebrun, J.J., Activin induces hepatocyte cell growth arrest through induction of the cyclin-dependent kinase inhibitor p15INK4B and Sp1. Cellular Signalling, 16, pp. 693-701, 2004. doi:10.1016/j.cellsig.2003.11.002

[53] Bouzahzah, B., Fu, M., Iavarone, A., Factor, V.M., Thorgeirsson, S.S. \& Pestell, R.G., Transforming growth factor- $\beta 1$ recruits histone deacetylase- 1 to a p130 repressor complex in transgenic mice in vivo. Cancer Research, 60, pp. 4531-4537, 2000.

[54] Sanderson, N., Factor, V., Nagy, P., Kopp, J., Kondaiah, P., Wakefield, L., Roberts, A.B., Sporn, M.B. \& Thorgeirsson, S.S., Hepatic expression of mature transforming growth factor $\beta 1$ in transgenic mice results in multiple tissue lesions. Proceedings of the National Academy of Sciences USA, 92, pp. 2572-2576, 1995. doi:10.1073/pnas.92.7.2572

[55] Oe, S., Lemmer, E.R., Conner, E.A., Factor, V.M., Leveen, P., Larsson, J., Karlsson, S. \& Thorgeirsson, S.S., Intact signaling by transforming growth factor $\beta$ is not required for termination of liver regeneration in mice. Hepatology, 40, pp. 1098-1105, 2004. doi:10.1002/hep.20426

[56] Romero-Gallo, J., Sozmen, E.G., Chytil, A., Russell, W.E., Whitehead, R., Parks, W.T., Holdren, M.S., Her, M.F., Gautam, S., Magnuson, M., Moses, H.L. \& Grady, W.M., Inactivation of TGF- $\beta$ signaling in hepatocytes results in an increased proliferative response after partial hepatectomy. Oncogene, 24, pp. 3028-3041, 2005. doi:10.1038/sj.onc.1208475 
[57] Yasuda, H., Mine, T., Shibata, H., Eto, Y., Hasegawa, Y., Takeuchi, T., Asano, S. \& Kojima, I., Activin A: an autocrine inhibitor of initiation of DNA synthesis in rat hepatocytes. Journal of Clinical Investigations, 92, pp. 1491-1496, 1993. doi:10.1172/JCI116727

[58] Ju, W., Ogawa, A., Heyer, J., Nierhof, D., Yu, L., Kucherlapati, R., Shafritz, D.A. \& Bottinger, E.P., Deletion of Smad2 in mouse liver reveals novel functions in hepatocyte growth and differentiation. Molecular and Cellular Biology, 26, pp. 654-667, 2006. doi:10.1128/MCB.26.2.654-667.2006

[59] Ikeda, H., Satoh, H., Yanase, M., Inoue, Y., Tomiya, T., Arai, M., Tejima, K., Nagashima, K., Maekawa, H., Yahagi, N., Yatomi, Y., Sakurada, S., Takuwa, Y., Ogata, I., Kimura, S., \& Fujiwara, K., Antiproliferative property of sphingosine 1-phosphate in rat hepatocytes involves activation of Rho via Edg-5. Gastroenterology, 124, pp. 459-469, 2003. doi:10.1053/ gast.2003.50049

[60] Sakamoto, T., Liu, Z., Murase, N., Ezure, T., Yokomuro, S., Poli, V. \& Demetris, A.J., Mitosis and apoptosis in the liver of interleukin-6-deficient mice after partial hepatectomy. Hepatology, 29, pp. 403-411, 1999. doi:10.1002/hep.510290244

[61] Sandgren, E.P., Palmiter, R.D., Heckel, J.L., Daugherty, C.C., Brinster, R.L. \& Degen, J.L., Complete hepatic regeneration after somatic deletion of an albumin-plasminogen activator transgene. Cell, 66, pp. 245-256, 1991. doi:10.1016/0092-8674(91)90615-6

[62] Rhim, J.A., Sandgren, E.P., Palmiter, R.D. \& Brinster, R.L., Complete reconstitution of mouse liver with xenogeneic hepatocytes. Proceedings of the National Academy of Sciences USA, 92, pp. 4942-4946, 1995. doi:10.1073/pnas.92.11.4942

[63] Tateno, C., Yoshizane, Y., Saito, N., Kataoka, M., Utoh, R., Yamasaki, C., Tachibana, A., Soeno, Y., Asahina, K., Hino, H., Asahara, T., Yokoi, T., Furukawa, T. \& Yoshizato, K., Near completely humanized liver in mice shows human-type metabolic responses to drugs. American Journal of Pathology, 165, pp. 901-912, 2004.

[64] Emoto, K., Tateno, C., Hino, H., Amano, H., Imaoka, Y., Asahina, K., Asahara, T. \& Yoshizato, $\mathrm{K}$., Efficient in vivo xenogeneic retroviral vector-mediated gene transduction into human hepatocytes. Human Gene Therapy, 16, pp. 1138-1174, 2005. doi:10.1089/hum.2005.16.1168 